\title{
Total and free thyroid hormone concentrations in patients receiving maintenance replacement treatment with thyroxine
}

\author{
C J PEARCE, R L HIMSWORTH
}

\begin{abstract}
Total and free serum concentrations of thyroxine and triiodothyronine were measured in 122 subjects with hypothyroidism who were clinically well while receiving conventional replacement treatment with thyroxine. In a third of patients concentrations of total and free thyroxine were raised, often considerably; nevertheless concentrations of total and free triiodothyronine were usually normal. Though significant correlations were obtained between total triiodothyronine concentrations and total thyroxine concentrations $(p<0.001)$ and between the triiodothyronine concentrations and free thyroxine concentrations $(p<0.001)$ the slope of the line of the regression equation describing these correlations was small, hence large increases in both total and free thyroxine concentrations were accompanied by only modest increases in total and free triiodothyronine concentrations.

The presence of total or free thyroxine concentrations above normal in patients taking thyroxine therefore are not necessarily of clinical consequence. In the assessment of adequacy of replacement treatment with thyroxine the most logical combination of in vitro thyroid function test results may be a normal thyrotrophin concentration and normal free triiodothyronine concentration.
\end{abstract}

\footnotetext{
Endocrinology Research Group, Clinical Research Centre and Northwick Park Hospital, Harrow HA1 3UJ

C J PEARCE, BM, MRCP, honorary senior registrar

R L HIMSWORTH, MD, FRCP, consultant physician

Correspondence to: Dr R L Himsworth.
}

\section{Introduction}

Hypothyroidism is a common disorder ${ }^{1}$ and practitioners in all specialties will encounter such patients who are treated with thyroxine. Though the efficacy of replacement treatment is without doubt, the niceties of dose regulation are still imperfectly understood despite the introduction of radioimmunoassays for the precise measurement of the concentration of hormones in serum. The interpretation of results of assays for total thyroxine concentration is complicated, firstly because the hormones are largely protein bound, and it is the concentration of free hormone that is physiologically important, and secondly because the conversion of thyroxine to the biologically effective triiodothyronine is now recognised as a crucial stage in the expression of thyroid hormone activity.

The original treatment for hypothyroidism was thyroid extract, a variable mixture of thyroxine and triiodothyronine, but this has now been superseded in Britain by pure synthetic thyroxine. For many years it was accepted practice to prescribe thyroxine in doses from 200 to $400 \mu \mathrm{g}$ daily. With the introduction of radioimmunoassay it was found that total plasma thyroxine concentrations in patients receiving these doses might be comparable to those in patients with hyperthyroidism. Nevertheless, the patients treated with thyroxine only rarely showed signs or symptoms of toxicity. It was later shown that the raised plasma thyroid stimulating hormone concentration of primary hyperthyroidism could be brought back into the normal range with smaller amounts of thyroxine, ${ }^{2}$ and the usual maintenance dose now recommended is from 100 to $200 \mu \mathrm{g}$ daily. Even on this reduced regimen, however, total concentrations of thyroxine may still exceed the conventional upper limit of the normal range.

It is now generally believed that thyroxine itself is an inactive prohormone requiring conversion to triiodothyronine by de- 
iodination in the peripheral tissues. ${ }^{3}$ Total plasma concentration of triiodothyronine in patients receiving large doses of thyroxine is not unduly increased; in patients with untreated hyperthyroidism, however, high triiodothyronine concentrations are the direct result of excess production from the thyroid gland. Nevertheless, the exact situation has been unclear because thyroxine is more strongly bound by the thyroxine binding globulin, and will therefore displace triiodothyronine. Free triiodothyronine concentrations in patients receiving conventional or excessive doses of thyroxine might therefore be very different from normal.

With these considerations in mind we have used newly introduced assays for concentrations of free thyroxine and free triiodothyronine to study the interrelations of bound and free thyroid hormones in a large group of patients with hypothyroidism stabilised with what would currently be regarded as conventional replacement treatment.

\section{Patients and methods}

Serum samples were obtained from 122 patients attending the endocrine clinic at Northwick Park Hospital and stored at $-20^{\circ} \mathrm{C}$ before assay. Primary hypothyroidism had been diagnosed on conventional clinical and biochemical grounds, and all patients had been stabilised with the administration of their respective doses of thyroxine for three months or longer. All were in good health and clinically euthyroid at the time of sampling, and none was taking any medication known to interfere with the metabolism or plasma binding of the thyroid hormones. Eighteen $(15 \%)$ patients were taking $100 \mu \mathrm{g}$ thyroxine daily, $29(23 \%)$ were taking $150 \mu \mathrm{g}, 72(59 \%)$ were taking $200 \mu \mathrm{g}$, and only three were taking $300 \mu$ g daily. One hundred and three $(85 \%)$ subjects were women, mean age 59 years (range 33-86, SD 12); $19(15 \%)$ were men, mean age 62 years (range $42-80$, SD 14 ).

Total thyroxine and triiodothyronine concentrations were measured by radioimmunoassay. Where high concentrations of thyroxine were encountered the sample was diluted with serum which contained no thyroid hormone and was reassayed. The interassay and intra-assay coefficients of variation were total thyroxine 5.4 and $7.1 \%$, and total triiodothyronine 6.2 and $8.1 \%$, respectively. Thyrotrophin concentration was also measured by radioimmunoassay. Both free thyroxine and free triiodothyronine concentrations were measured by a newly introduced radioimmunoassay method (Amerlex, Amersham International) based on the use of a tracer analogue that is not bound by thyroxine binding globulin. The interassay and intra-assay coefficients of variation of these assays were, respectively: free thyroxine concentration 5.2 and $6.4 \%$, and free triiodothyronine concentration 6.2 and $8 \cdot 1 \%$.

\section{Results}

Figures 1 and 2 show the data in graphical form. The serum concentration of total thyroxine in these clinically euthyroid subjects ranged from 75 to $222 \mathrm{nmol} / 1$, mean 135, SD 31; normal range 60$150 \mathrm{nmol} / 1(5 \cdot 8-17 \cdot 2 \mu \mathrm{g} / 100 \mathrm{ml}$, mean $10 \cdot 5$, SD $2 \cdot 4$; normal range $4.7-11.7 \mu \mathrm{g} / 100 \mathrm{ml})$ and concentration of total triiodothyronine ranged from 1.5 to $3.3 \mathrm{nmol} / 1$, mean $2 \cdot 3$, SD 0.37 ; normal range $1 \cdot 2 \cdot 3 \cdot 1 \mathrm{nmol} /$ $1(0 \cdot 97-2 \cdot 15 \mathrm{ng} / \mathrm{ml}$, mean $1 \cdot 5$, SD $0 \cdot 24$; normal range $0 \cdot 78-2 \cdot 92 \mathrm{ng} / \mathrm{ml})$. The concentrations of free thyroxine varied from 9 to $60 \mathrm{pmol} / \mathrm{l}$, mean 22.7, SD 10.7; normal range 6-22 pmol/1 (0.69 and 4.66 ng/ $100 \mathrm{ml}$, mean $1 \cdot 76$, SD 0.83 ; normal range $0.46-1 \cdot 71 \mathrm{ng} / 100 \mathrm{ml}$ ) and concentration of free triiodothyronine was from 3.7 to $10.4 \mathrm{pmol} / \mathrm{l}$, mean 5.9, SD 1.5 ; normal range $2 \cdot 8-8.7 \mathrm{pmol} / 1(2 \cdot 41-6.77 \mathrm{pg} / \mathrm{ml}$, mean $3 \cdot 8$, SD $0 \cdot 9$; normal range $1 \cdot 8-5 \cdot 7 \mathrm{pg} / \mathrm{ml}$ ). In all these patients the secretion of thyroid stimulating hormone was normal or suppressed $(<4.0 \mathrm{mU} / \mathrm{l})$.

The correlation coefficient between total and free thyroxine concentrations was 0.54 (free thyroxine $\mathrm{pmol} / 1=0.179$ total thyroxine $\mathrm{nmol} / \mathrm{l}-2 \cdot 06)$ and between concentrations of total and free triiodothyronine the correlation coefficient was 0.46 (free triiodothyronine $\mathrm{pmol} / \mathrm{l}=1.86$ total triiodothyronine $\mathrm{nmol} / 1+1.53$ ). The corresponding linear correlation coefficient between concentrations of total thyroxine and total triiodothyronine (fig 1) was $0.53(\mathrm{p}<0.001)$ and between concentrations of free thyroxine and free triiodothyronine (fig 2) was $0.71(p \ll 0.001)$. Attempts to fit the data points to a non-linear function produced less significant correlations.

\section{Discussion}

Thirty years ago triiodothyronine was identified in the serum of normal subjects ${ }^{4}$ and was later detected in an athyreotic patient treated with thyroxine. ${ }^{5}$ This early demonstration of extrathyroidal conversion of thyroxine to triiodothyronine was not confirmed, however, until the introduction of sensitive and specific radioimmunoassays. ${ }^{6}$ Kinetic studies both in normal subjects and in patients taking thyroxine then showed that most of the daily production of triiodothyronine in normal subjects, and all the daily production in patients having treatment, was by deiodination of thyroxine in the peripheral tissues. Most authorities now believe that thyroxine is in effect a prohormone requiring conversion to triiodothyronine before a thyromimetic effect is seen. This peripheral deiodination of thyroxine is another step in the organisation of thyroid hormone activity at which the regulation of metabolism might be influenced. It is not yet certain, however, that control is exercised at this stage. Nevertheless, it is known that under some conditions the production of triiodothyronine falls as a result of diminished deiodination of thyroxine ${ }^{8}$ and concomitantly there is an accumulation of the other major metabolite of thyroxine, reverse triiodothyronine, a compound devoid of thyromimetic effect. The mechanisms that determine these reactions of deiodination are as yet unclear, as is the extent to which they may be purposefully controlled under different conditions. There is some evidence to suggest that in untreated hypothyroidism the fractional conversion rate of thyroxine to triiodothyronine is increased. ${ }^{9}$ The interrelations of the thyroid hormones in patients with hypothyroidism who are being given replacement treatment with thyroxine are therefore of physiological interest and clinical importance.

In the present study concentrations of both total and free thyroxine and triidothyronine have been measured in serum from a large number of healthy subjects who had hypothyroidism and were stabilised by treatment with thyroxine. As secretion of thyroid stimulating hormone was subdued in all any possible residual secretion of triiodothyronine by the thyroid was presumed to be negligible. In 39 subjects $(32 \%)$ the total thyroxine concentration was raised, often to considerably above the upper limit of normal, a common finding even in patients maintained on the now conventional dosage of thyroxine, but in only five of these patients was total triiodothyronine marginally above the normal range (fig 1). If the total concentration of thyroxine is high the occupancy of binding sites on thyroxine binding globulin will be increased, and the less strongly bound triiodothyronine may be displaced; a high total thyroxine concentration, therefore, might cause both an increase in free thyroxine and free triiodothyronine concentrations despite normal concentrations

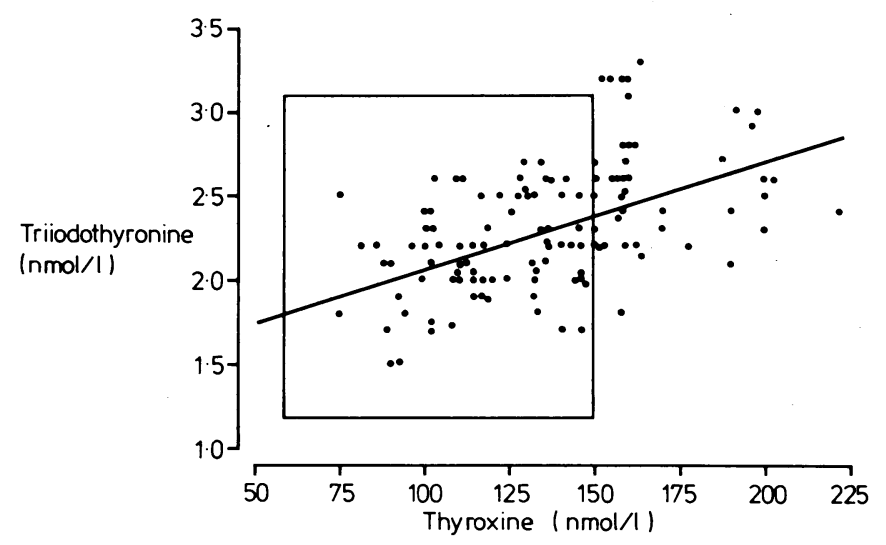

FIG 1-Total serum concentrations of thyroxine and triiodothyronine in 122 patients with hypothyroidism on replacement with thyroxine. Linear correlation $r=0.53(p<0.001$; total triiodothyronine $=0.0064$ total thyroxine +1.42 ). The range of normal is shown by the box.

Conversion: SI to traditional units-Thyroxine $1 \mathrm{nmol} / 1 \approx 0.07 \mu \mathrm{g} / 100 \mathrm{ml}$; triiodothyronine $1 \mathrm{nmol} / 1 \approx 0.65 \mathrm{ng} / \mathrm{ml}$. 
of total triiodothyronine. This was not found to be the case. In 52 subjects the free thyroxine concentration was raised, often considerably (fig 2), yet in only eight was the free triiodothyronine concentration slightly raised.

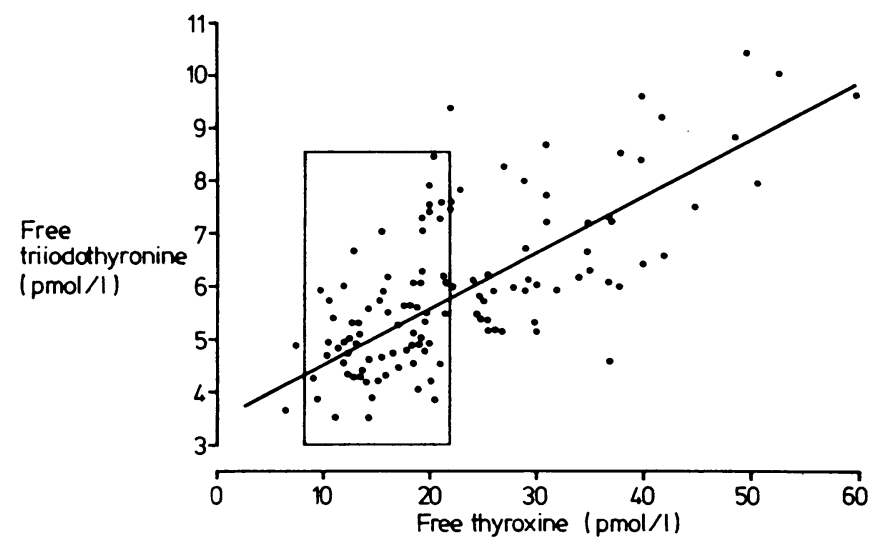

FIG 2-Free serum concentrations of thyroxine and triiodothyronine in 122 patients with hypothyroidism on replacement with thyroxine. Linear correlation $r=0.71(p \ll 0.001$; free triiodothyronine $=0.105$ free thyroxine +3.52 ). The range of normal is within the box.

Conversion: SI to traditional units-Thyroxine $1 \mathrm{pmol} / 1 \approx 0.07 \mathrm{ng} / 100 \mathrm{ml}$; triiodothyronine $1 \mathrm{pmol} / 1 \approx 0.65 \mathrm{pg} / \mathrm{ml}$.

Although statistical analysis of the data yielded significant correlations between total thyroxine and total triiodothyronine concentrations and between free thyroxine and free triiodothyronine concentrations, the slopes of the lines of the regression equations describing these correlations were small-that is, large increases in total and free thyroxine concentrations were accompanied by only modest increases in total and free triiodothyronine concentrations. These findings are in broad agreement with those of an earlier study of concentrations of free thyroid hormones, measured by a different technique in a smaller group of patients taking thyroxine. ${ }^{10}$ The authors of this study suggested that supraphysiological free thyroxine concentrations were not harmful because free triiodothyronine was maintained within normal limits by a modulation of the peripheral reactions of deiodination. We urge caution, however, in extrapolating from data on serum concentration to inferences concerning the kinetics of the metabolism of thyroxine. Whether or not production of triiodothyronine at high concentrations of thyroxine is controlled to maintain a relatively normal free triiodothyronine concentration can be decided only by the appropriate kinetic experiments. Whatever the underlying explanation, the main practical conclusion is clear-namely, that supraphysiological free thyroxine concentrations are not necessarily accompanied by an increase in the free triiodothyronine concentration above the normal range.

What is the relevance of these findings? It is the common experience that no characteristic pathology develops in patients treated for hypothyroidism even after many years, nor is life expectancy diminished. Moreover, this knowledge is derived from a period when larger doses of thyroid hormones were given than are now customary. It seems, therefore, that though physiological measurements in such patients can show evidence for overexposure to thyroid hormones, ${ }^{211}$ there are no deleterious biological consequences of this lack of fine tuning of dosage. This is in distinct contrast to the findings in insulin dependent diabetes, but in insulin dependent diabetes the hormone is immediately effective and does not require activation in peripheral tissues. It seems from measurements of concentrations of free thyroid hormone that there is a safe latitude in dosage of thyroxine. In our experience the discovery of high total thyroxine concentrations in otherwise well subjects with hypothyroidism who are taking thyroxine often generates unwarranted concern in both doctor and patient. Though it may well be prudent to reduce the dose in a patient whose concentration of total or free thyroxine is considerably raised, because the free triiodothyronine concentration may thus also be somewhat increased, few such patients show symptoms or signs of hyperthyroidism.

The past decade has witnessed an extraordinary proliferation in the number and variety of in vitro thyroid function tests available to the clinician, and the hard pressed general physician might with some justification deprecate the introduction of yet another. There has been a logic behind the development of these assays, however, based on two central tenets of thyroid physiology; firstly, the fact that the thyroid hormones are almost totally protein bound in the serum, and the minute free fraction is the physiologically important moiety, and secondly, the concept of thyroxine as an inactive prohormone, requiring conversion to triiodothyronine before a thyromimetic effect is seen. Since the protein bound iodine was displaced by the advent of radioimmunoassay for total thyroxine concentration, there have been introduced successively a free thyroxine index, total thyroxine related to thyroxine binding globulin, assays for total triiodothyronine concentrations, free thyroxine concentrations, and now free triiodothyronine concentrations. The data described in this paper suggest that in the assessment of patients receiving treatment with thyroxine, the most helpful investigations are those showing normal concentrations of thyroid stimulating hormone-that is, sufficient replacement-and those showing normal free triiodothyronine concentration (dosage not excessive). What is still required, however, is a single, simple, sensitive, and specific index of thyroid hormone activity at the tissue level; in the meantime the physician must select those investigations that seem most appropriate in the clinical context, and perhaps make greater use of the oldest thyroid test of all-the careful history and examination of the patient.

We are grateful to the many colleagues who have allowed us to study patients under their care, and to Dr Michael Rinsler and the staff of the department of Clinical Chemistry, Northwick Park Hospital, who helped with the assays and collection of serum samples. Amersham International provided Amerlex kits for the assay of free thyroid hormones.

\section{References}

1 Tunbridge WMG, Evered DC, Hall R, et al. The spectrum of thyroid disease in a community: the Whickam survey. Clin Endocrinol (Oxf) $1977 ; 7: 481-93$.

2 Evered DC, Young ET, Ormston BJ, Menzies R, Smith PA, Hall R. Treatment of hypothyroidism: a reappraisal of thyroxine replacement therapy. Br Med F 1973;iii:131-4.

${ }^{3}$ Larsen PR, Silva JE, Kaplan MM. Relationships between circulating and intracellular thyroid hormones: physiological and clinical implications. Endocrine Reviews 1982;2:87-102.

4 Gross J, Pitt-Rivers R. The identification of 3,5,3' triiodothyronine in human plasma. Lancet $1952 ; \mathrm{i}: 439-41$.

5 Pitt-Rivers R, Stanbury J, Rapp B. Conversion of thyroxine to 3,5,3' triiodothyronine in vivo. Fournal of Clinical Endocrinology and Metabolism 1955;15:616-20.

${ }^{6}$ Braverman LE, Ingbar SH, Sterling K. Conversion of thyroxine (T4) to triiodothyronine (T3) in athyreotic human subjects. $\mathcal{f}$ Clin Invest 1970;49:855-64.

7 Surks MI, Schadlow AR, Stock JM, Oppenheimer JH. Determination of iodothyronine absorption and conversion of L-thyroxine to L-triiodothyronine using turnover rate techniques. F Clin Invest 1973;52: 805-11.

${ }^{8}$ Chopra IJ. Triiodothyronines in health and disease. Monogr Endocrinol $1981 ; 18: 100$.

9 Inada M, Kasagi K, Kurata $S$, et al. Estimation of thyroxine and triiodothyronine distribution and the conversion rate of thyroxine to triiodothyronine in man. $\mathcal{F}$ Clin Invest 1975;55:1337-48.

10 Kurtz AB, Dwyer K, Capper SJ, von Borcke S, Ekins RP. Free thyroid hormone concentrations in serum from patients on thyroxine replacement therapy. Nuclear Medicine Communications 1980;1:28-32.

11 Bell GM, Sawyers JSA, Forfar JC, Doig A, Toft AD. The effect of minor increments in plasma thyroxine on heart rate and urinary sodium excretion. Clin Endocrinol (Oxf) 1983;18:511-6.

(Accepted 10 November 1983; 